\title{
Fostering Critical Self-reflection among PGCE Students: A Case of Micro-teaching Practices
}

\author{
Letlhoyo Segalo \\ Department of Educational \& Professional Studies, PO Box 1881, Central University of Technology, Welkom Campus, South Africa
}

Received May 22, 2021; Revised July 20, 2021; Accepted August 22, 2021

\section{Cite This Paper in the following Citation Styles}

(a): [1] Letlhoyo Segalo, "Fostering Critical Self-reflection among PGCE Students: A Case of Micro-teaching Practices," Universal Journal of Educational Research, Vol. 9, No. 10, pp. 1725 - 1731, 2021. DOI: 10.13189/ujer.2021.091001.

(b): Letlhoyo Segalo (2021). Fostering Critical Self-reflection among PGCE Students: A Case of Micro-teaching Practices. Universal Journal of Educational Research, 9(10), 1725 - 1731. DOI: 10.13189/ujer.2021.091001.

Copyright $\odot 2021$ by authors, all rights reserved. Authors agree that this article remains permanently open access under the terms of the Creative Commons Attribution License 4.0 International License

\begin{abstract}
This paper explored a fostered critical self-reflection among Postgraduate Certificate in Education (PGCE) students after their micro-teaching sessions. During the first and second micro-teaching sessions, student teachers attend to the pre-lesson phase; and the actual teaching focuses on the mastering of skills such as lesson planning, use of instructional teaching media, management of classroom activities and questioning skills, among others. In return, student teachers are provided with written and face-to-face feedback or a video recording as a third option. These three approaches are employed by lecturers to assist student teachers to critically reflect on their own progress and practices. The aim of the research study was to explore the use of critical reflection PGCE students after micro-lesson exposure. Vygotsky's theory of Zone of Proximal Development (ZPD) was used to demonstrate that a scaffolded self-critical reflection in a micro-teaching can be useful. This study used a qualitative research approach. A purposive sample of 16 students was selected with the aim to broaden the understanding of self-critical assessment within a micro-teaching context. An open-ended questionnaire was used to collect data which was later analysed categorically into different themes, according to the items responded to by the students. The findings showed that PGCE students are able to apply critical self-reflection as a skill to enhance and confront teaching problems at a very limited scale. Furthermore, the study revealed that PGCE students find it challenging to critique themselves using various tools such as video-recordings, reflective journaling among others within Vygotsky's
\end{abstract}

ZPD.

Keywords Critical Self-reflection, Micro-managed, Micro-teaching Practice, PGCE Students, University of Technology, Zone of Proximal Development

\section{Introduction}

The Postgraduate Certificate in Education programme is offered at many South African universities as a professional teaching qualification. The programme is presented over a period of one or two years to full-time and part-time students, respectively. Students who are admitted to this programme have primary qualifications in the form of a wide variety of bachelor's degrees and three-year diplomas, without a background in education or teaching foundations. The challenge lies in systematically orientating them to the teaching profession. The swift adaptation and socialisation of PGCE students as teachers remain a critical challenge, among others. Thus, micro-teaching sessions are used as a catalyst to accelerate and adapt PGCE students to teach within a secure and unthreatening environment using different modes of teaching skills [1][2]. Accordingly, one may view micro-teaching as a micro-managed teaching laboratory for student teachers to hone their teaching skills for professional purposes [3][4][5].

At one university of technology in South Africa, micro-teaching sessions are scheduled four times a year, 
once every quarter of the year. Student teachers' teaching exposure may include the use of chalkboards or whiteboards, integration of posters, the use of models and the use of overhead projectors to clarify the subject that is taught [6]. Furthermore, student teachers are also exposed to the management of the classroom environment in such a way as to ensure that imminent and simultaneous learner needs are attended to. Consequently, [7][8][9] remark that it is envisaged that micro-teaching will be a helpful scaffold for PGCE students to deal with a more demanding macro-classroom environment in a real school where there are a variety of learner challenges such as classroom indiscipline, focus on task and on-going assessment. Against the backdrop of the above-mentioned, this research study is focussed on the ability of PGCE students to critically assess themselves to enhance their teaching skills.

According to Maarof, (2007) and Lee, (2008) [10][11] reflective learning could be assumed to be an active and deliberate process through which a teaching experience is recalled, considered, and evaluated in relation to a particular question the student teacher may harbour regarding his or her teaching abilities. As such, reflective teaching may further be described as a self-confrontational process where the student teachers take a hard look at their professional trajectories with the sole purpose of improving mastering the teaching environment amid fears of failure and weaknesses. [12][13][14] mention that self-reflective learning could be regarded as a high-order cognitive process where the student teacher, as teaching practitioner, evaluates his or her past experiences and decides on what to do better or differently in the future [15][16]. The use of reflection as a practice suggests a thoughtful and voluntary effort that a student teacher engages in order to establish a set of beliefs upon his or her practice of teaching [17]. [18] refers to Schon as a scholar who focused on rational reflection within the understanding and development of professional practice such as student teachers' training [18]. The basis of Schon's rational reflection aims to improve a set of professional practices, which could lead to a state of expertise in that field. [16] states that Schon identified two modes of critical reflection, which are, reflection in action and reflection on action. Reflection in action is what the student teacher is likely to experience while teaching in the micro-teaching teaching lesson, whereas reflection on action can be considered a postfacto experience. [19] Reflection on action is likely to occur after the student teacher has presented a lesson and received feedback from mentor lecturer, peer students and in some instances from the lesson video recording. Thus, reflection on action will involve the student teacher deliberately engaging self in the micro-teaching event that occurred by means of reviewing, analysing and evaluating how future teaching related problems could be improved. Purposive critical reflection implies an interest for the student teacher to be contemplative, making informed professional judgements, identifying personal strengths and limitations [18]. Critical reflection on action indicates high order metacognitive process in terms of Bloom's taxonomy of knowledge with the intention for the student teacher to challenge his or her self-held assumptions about content knowledge being taught and the pedagogical strategies employed in the micro-teaching environment [21]. [14] further states that critical self-reflection is a positive sign of maturity, openness and a room for self-check and self-knowledge about one's context, constrains and allowing control over one' own direction in the teaching milieu.

[19][20] reason that student teachers should be given the space to express their personal expressions in order to address the myriad of the teaching practice with the assistance of their lecturers or co-students. In advancing the agenda for reflective learning, Habermas suggests that critical reflection should be the basis of transformative learning for the student teacher [20]. Critical reflection suggests that student teachers should be conscious of the inherent challenges in their teaching spaces [21]. In this way, by critically reflecting, student teachers are liberated from the limitations of their teaching spaces and enabled to negotiate supporting spaces, rather than reproducing those inhibiting spaces. [22][23] suggest that liberating reflection embedded in critical reflection allows the student teacher to explore situations in which he or she felt disempowered with the aim of facilitating empowerment with the eventual freedom.

\section{Theoretical Framework}

The Zone of Proximal Development (ZPD) theory based on Vygotsky was fit for this paper within a reflective learning culture pursued by student teachers. Vygotsky's zone of proximal development was created with child development in mind, in the context of this study, student teachers' harnessing, and training are viewed in the same light. [24][25], one major aspect of Vygotsky's theory is the idea that the potential for cognitive development depends upon the "zone of proximal development" (ZPD): a level of development attained when student teachers' engage in professional behaviors associated with the appropriate teaching skills in their own fields of specialties. The development of the ZPD depends upon full mastering of the professional functions associated with teaching through regulated guidance in the form of micro-teaching the student teacher is afforded a space to try and test a range of didactical skills that can be developed with adult guidance or peer collaboration which will exceeds what can be attained alone. In the micro-teaching environment [25], mentions that difficult didactical tasks are broken inro manageable chunks, for example, learners are divided into small 
numbers from ten to fifteen instead of 30 and above, and fifteen minutes instead of forty-five minutes of teaching time is used. The micro-teaching environment classroom could be seen in the same way as a scaffold representing the distance between the actual developmental level as determined by independent problem-solving and the level of potential development, which is the macro-teaching classroom. As it was stated earlier in this paper, PGCE students enters this teaching professional programme with little knowledge foundations of educations, micro-teaching as one of the many scaffolds enables them to reach to the desired competencies of teaching in a macro-classroom.

[26] to fully appreciate how Vygotsky conceived of the ZPD requires going beyond standard definition of the construct and delving briefly into its historical origins. Vygotsky's thinking on the ZPD apparently began to crystallize as he confronted issues related to Intelligence Quotient (IQ) and IQ testing, which during his time was controversial. [27] argued that one could not fully understand children's developmental levels without also determining that upper boundary of development, which was determined by the kind of tasks that children could do with someone else's assistance. [28], in other words, two children might exhibit the same IQ score, supposedly indicating that they had achieved the same developmental level and thus readiness for instruction, but one of them might well be able to perform more complex tasks under someone else's guidance than the other could with the same assistance. Vygotsky referred to this difference between actual and potential IQ as the Zone of Proximal Development. [29] argued that some children might have a high IQ but a small ZPD and others might have a low IQ but a large ZPD. On the other hand, some children might have a high IQ and a large ZPD and, likewise, others might have a low IQ and a small ZPD [30].

Similarly, the ZPD in the confinement of micro-teaching scenario takes into consideration the importance of prior knowledge of student teachers, their experiences as adult learners, parents and other forms of knowledge that informs the stratum of their identities [31]. Furthermore, this student teachers while receiving guidance from their mentor lecturers also engages in conversations with themselves, their fellow students they teach and the pedagogical content they teach. In many ways, [25] says that ZPD allows them to reconstruct and construct new knowledges as they near their zones of maxims as the knowledge they teach takes different forms and shapes from the incept of the PGCE programme.

\section{Purpose of the Study}

The purpose of this research study was to explore the critical self-reflective practices of PGCE students against their experiences in a micro-teaching environment. The following research question guided the study:
How do PGCE student teachers use critical self-reflection post micro-lesson exposure to enhance their teaching proficiency?

\section{Research Methodology}

\subsection{Research Design and Method}

This study investigates the naturally occurring experiences of PGCE students during their critical self-assessment in the micro-teaching milieu [32]. A phenomenological interpretivist research approach was adopted in the study. This approach seeks a deeper understanding of the modes of critical self-assessment that PGCE students use rather than to generalise the findings of the study. [33] [34] have the view that studied realities - in the context of this study, those of PGCE students' assessment of their own teaching trajectories by acknowledging their subjective experiences as they reflect on their experiences during different micro-teaching process. A phenomenological interpretivism research framework of allows participants freedom to provide insights on their own practices as they are probed and able to reflect on their positions and teaching philosophies.

\subsection{Participants and Context of the Micro-teaching}

The participants of this research study were PGCE student teachers from a university of technology in South Africa. Sixteen participants aged between 23 and 28 took part in the study. They did not have any teaching experience prior to their admission to the PGCE programme. These students were previously enrolled in different academic programmes from Language and Communication, Management Sciences and Information and Technology Departments. The prior knowledge of these PGCE students could be described as tacit knowledge that is based on subject knowledge, intuition and cultural beliefs as opposed to explicit knowledge which can adapt to fit in new situations and are goal oriented. The subject knowledge which could be Economics must be transformed in how it is taught to different learners in different contexts using known pedagogical practices. To achieve this transformation, micro-teaching practices at the sampled university of technology are stratified in what could be referred as ZPD, four times in a year. Each quarter student teachers engages in elementary skills such as chalkboard writing, teaching, the use of media such as PowerPoint presentation, sculpting or using models to more complicated instructional teaching modes such as self-created teaching learning media to transform content knowledge into acceptable pedagogical knowledge [25]. Each micro-teaching is intensely supervised by the mentor lecturers to ascertain the progression of the student teacher 
in the form of the choice of lesson topic to be taught, the aim of the lesson and objectives, the tempo of the teaching, management of the classroom situation, the use of appropriate examples, the ask of questions during and after the lesson and tasks given as an expanded knowledge. The four quarter process of micro teaching allows student teachers in the PGCE programme to teach a lesson, assess the lesson, re-teach the lesson with new experience and to reflect again on how to teach another lesson in an enjoyable environment [9]. The process of micro-teaching affords each lesson to be educative where student teachers learn from their mistakes and are scaffolded to make appropriate pedagogical adjustments.

\subsection{Data Collection and Procedure}

An open-ended questionnaire was used to collect data from the sixteen PGCE student teachers. The aim was to establish a focused conversation on critical self-reflection after a micro-teaching experience [35] in order to determine their subjective views regarding fears of teaching, how they confront their own fears and their future aspirations as professional teachers [36][37].

Permission to conduct research was granted by the University Ethics Committee and the participants in this study consented individually [38]. They were informed of the aim of the study, research method and the importance of their participation. In order to ensure data trustworthiness, the method of interpretive validity was applied where the researcher and the researched mutually described and constructed their experiences of micro-teaching and self critical reflection [39][40]. The researchers relied on a peer review and member check to ensure the trustworthiness of the data collected that it was not compromised by the power relations of the student and lecturer. In this context of the study, data collected was collected by a neutral person. During the peer review, both the researchers and a senior advisor individually transcribed the open-ended questionnaire. For the member check, the researchers went back to the participants to verify and confirm the findings.

\subsection{Data Analysis and Presentation}

To ensure that the collected data produced findings that described the critical self-reflective assessment of the participating PGCE students regarding their micro-teaching experiences, a thematic data analysis was employed [41]. The validity of the themes are substantiated alongside the literature control referencing related to critical reflective learning and micro-teaching experiences. The following were the key themes that developed from the analysis:

\section{Theme 1: Modes of critical self-reflection}

This theme arose from the question: How do you reflect on your micro-teaching experience? In general, there are various ways through which a student teacher can reflect on personal learning experiences regarding aspects such as teaching methodologies, learner involvement, different learning contexts and assessment strategies. Methods may include the use of reflective journals, group discussions, blogs, and portfolios [25][26]. The evidence derived from the reflective journaling was not substantially described, henceforth the use of further probing by means of open-ended questionnaire.

In this study, all the participant PGCE students used a portfolio of evidence as a recording tool of their learning experiences. Further, it was discovered that there was little on self-critical assessment, and only reflections on actual events that occurred in the classroom. For example, student teachers in their reflective journals only describes instances without confronting difficult questions such as, how I can improve, what have I learned and how to I use a different approach in the future [9][11]. For example, one male student responded by stating;

"Though I use a reflective journal as instructed, I feel that I have not written my reflections properly to show my learning experiences from micro lesson one to the last" "if I had a clear instruction from my mentor lecturer, possibly I would have provided a descriptive progression on how reflecting on post micro-teaching I would have probed my teaching much better"

As demonstrated, student teachers in the PGCE programme should be able to show how they have used critical reflecting as scaffolding processing during micro lessons. In the context of this study, this finding implies that mentor lecturers who are responsible for micro-teaching should be encouraged to make deliberate efforts to make student teachers aware of the importance of including critical self-reflection in their portfolio of evidence. As suggested by [30][31] in the ZPD, mentor lecturers should encourage student teachers to use other modes of reflections rather than the reflective journals to evaluate and improve on their teaching skills prowess. $65 \%$ of the student teachers showed that without critical self-reflection, participant PGCE students could not demonstrate their resilience against the teaching challenges they were confronted with in micro-teaching situations in real situation.

\section{Theme 2: Overcoming fears of self-critical assessment}

Furthermore, other modes of reflection such as watching the video recordings, group discussions and blogs should be included in the student teachers' assessment of their portfolios of evidence. How do you discuss your micro-teaching presentations after the presentation? This was another question directed at the student teachers. Responses from this question suggest that student teachers make the process of acquiring the skill of teaching a personal issue. For example, one female student response said:

"I hardly discuss what transpired in my micro-teaching 
lesson presentation with fellow students, though I know that there are mistakes to be corrected for improvement "I know that when I taught the objectives for the lesson where not followed by means of questions during and after the lesson and that made me afraid to look back on what mistakes I have committed"

One student wrote differently dispelling fears associated with self reflective learning by alluding to;

"I realized that my use of the chalkboard was not legible at the beginning of the micro-lesson which was of a concern as it affects one's personal confidence when teaching. I took personal responsibility to practice frequently the art of chalkboard writing. Now I feel at ease when I have to explain or write something on the chalkboard"

Self-critical reflection might be inhibited as shown by the above incept. [4][8] suggest that it is critical that student teachers confront their fears by taking a deep look at themselves and see self-criticism and reflection as a step towards scaffolding their didactical skills, rather, as not as a failure. Though the micro-lesson classrooms are fitted with video-recordings, student teachers responses indicate that they hardly review or replay their own lessons with an aim of improving their lesson deliveries. [4][5] found that the use of self-watch through a video after a lesson presentation has benefits such as, encouraged change, acquiring a new different perspective, taking responsibility to change own practice and being able to see their own progress. From this perspective, the use of a video recording could be used to demonstrate the actual development and the desired development, according to Vygotsky's Zone of Proximal Distance.

Theme 3: Linking teaching theory and practice

This theme sought to establish whether PGCE student teachers are able to link the teaching theories they have been taught to their teaching practices during the micro-teaching processes. This theme emerged from the question: What is your view of the importance of the application of teaching theory to your actual teaching practice? Studies done by [31] demonstrate that there is a huge gap between teaching theory and the application thereof among student teachers. Student teachers in this study had a difficulty in recollecting and deeply reflecting on how they could improve on the transference of the theoretical content with its application in a real setting. Nonetheless, one student who had an idea of self-critical learning reflected by stating:

"What I have learned about practical knowledge is that it can lead to a deeper understanding of the subject you teach through the act of one's personal experience. I now know that theoretical knowledge is the knowledge about the practical application and how I have acquired that knowledge for implementation in the classroom using appropriate teaching aids at a level

\section{appropriate for the grade or standard I teach"}

Another student stated:

"reflecting on what I have taught in the micro-teaching and feedback I received from mentor-lecturers opened my eyes that there are different approaches to teaching same subject for different purposes and different circumstances" I now know that I should be able to create my own teaching material that will be suitable for my class as the textbook is sometimes gives a general approach to teaching"

Therefore, a skill of explaining, demonstrating and visualizing was observed as being important towards the zone of proximal development in the PGCE students. This observation makes it necessary for mentor lecturer to expose these student teachers to a variety of teaching methods for them to practice and choose the correct one that suits their personalities, content being taught and a room to explore [29][28].

The findings of the study under this theme highlight the importance of orientating PGCE students towards a variety of teaching theories and their application to the actual teaching practice. All the student participants interviewed showed obliviousness of the importance of theoretical application to their teaching practices.

\section{Conclusions}

This research study highlights the importance of enhancing the skill of critical self-reflection in the teacher training programme. This is done against the framework of the training of PGCE student teachers at a university of technology in South Africa. The aim is to make student teachers aware that their teaching practices are not void of embedded philosophical teaching influences and must be appreciated as such. The findings of the study accept the brevity of the PGCE teaching programme and its intensity. This research study demonstrates that the training of student teachers to become teachers is not a linear process but a process where each lesson is monitored and improved. However, improvement comes in the form of critical reflection with the intent to improve and master the content as well as the pedagogical content afforded in the micro-teaching environment. Most importantly, critical reflection works as a platform that allows collaborative learning, individual, peers and mentors. By means of reflective learning, student teachers are likely to have a positive self-belief, trust in others and positive teaching self-efficacy. Self-critical reflection used during the micro teaching fitted the use of ZPD because it is a step-by-step mediated process for self-confidence. The shortcomings observed in the findings of this study such as a providing learner with appropriate different learning contexts and confronting self-inhibitions fears reveal that critical self-reflection should be strongly encouraged as a 
learning process to avoid pitfalls and repetitive mistakes committed by student teachers in the PGCE training programme. The study further suggests that other modes of reflective learning should be encouraged among PGCE students in order to foster their zone of proximal development.

\section{REFERENCES}

[1] Thakrar, Jayshree, Freda Wolfenden, and Denise Zinn. "Harnessing open educational resources to the challenges of teacher education in Sub-Saharan Africa." International Review of Research in Open and Distributed Learning 10(4), 2009. https://doi.org/10.19173/irrodl.v10i4.705.

[2] Dervent, Fatih. "The effect of reflective thinking on the teaching practices of preservice physical education teachers." Issues in Educational Research 25(3), 260-275. 2015.

[3] Kanwar, Asha, Balasubramanian Kodhandaraman, and Abdurrahman Umar. "Toward sustainable open education resources: A perspective from the global south." The Amer. Jrnl. of Distance Education 24(2), 65-80.2010.

[4] Tripp, Tonya, and Peter Rich. "Using video to analyze one's own teaching." British Journal of Educational Technology 43(4), 678-704. 2012. https://doi.org/10.1111/j.1467-8535. 2011.01234.x.

[5] Tripp, Tonya R., and Peter J. Rich. "The influence of video analysis on the process of teacher change." Teaching and teacher education 28(5), 728-739. 2012. https://doi.org/10.1016/j.tate.2012.01.011.

[6] Calandra, Brendan, Rachel Gurvitch, and Jacalyn Lund. "An exploratory study of digital video editing as a tool for teacher preparation." Journal of Technology and Teacher Education 16(2),137-153. 2008.

[7] Vu, Hai Ha, and Diana L. Dudzik. "Problematising pre-service English language teacher education curriculum." In Building Teacher Capacity in English Language Teaching in Vietnam, pp. 23-43. Routledge, 2019.

[8] Marsh, Brian, and Nick Mitchell. "The role of video in teacher professional development." Teacher Development 18(4), 403-417. 2014.https://doi.org/10.1080/13664530.20 14.938106 .

[9] Trede, Franziska, and Megan Smith. "Teaching reflective practice in practice settings: students' perceptions of their clinical educators." Teaching in higher education 17(5), 615-627. 2012.https://doi.org/10.1080/13562517.2012.658 558.

[10] Maarof, Nooreiny. "Telling his or her story through reflective journals." International education journal 8(1), 205-220.2007.

[11] Lee, Icy. "Fostering preservice reflection through response journals." Teacher Education Quarterly 35(1), 117-139. 2008. https://www.jstor.org/stable/23479034.
[12] Icy, L. E. E. "Writing Response Journals: What Do Pre-service Teachers Think?." 2006.

[13] Graham, Anne, and Renata Phelps. "'Being a Teacher': Developing Teacher Identity and Enhancing Practice Through Metacognitive and Reflective Learning Processes." Australian Journal of Teacher Education 27(2), 2. 2003. http://dx.doi.org/10.14221.

[14] $S \oslash$ reide, Gunn Elisabeth. "Narrative construction of teacher identity: Positioning and negotiation." Teachers and Teaching: theory and practice 12,(5), 527-547. 2006.

[15] Rein, Martin, and Donald Schön. "Reframing policy discourse." In The argumentative turn in policy analysis and planning, 145-166. Duke University Press, 2013.

[16] Boud, David. "Using journal writing to enhance reflective practice." New directions for adult and continuing education 2001, 90, 9-18.2001.

[17] Hiemstra, Roger. "Uses and benefits of journal writing." New directions for adult and continuing education 2001, 90(1),9. 2001.

[18] Lucas, Patricia. "Critical reflection. What do we really mean." In 2012 Australian Collaborative Education Network National Conference, 163. 2012.

[19] Boud, David. "Creating a work-based curriculum." Work-based learning: A new higher education, 44-58.2001.

[20] Morrow, Elizabeth. "Teaching critical reflection in healthcare professional education." 2009.

[21] Lipp, Allyson. "An exploration of Taylor's reflective framework." Contemporary nurse 19(1-2), 88-95.2005.

[22] Taylor, Beverley Joan. "Walking my talk: applying the REFLECT model to personal-professional intersections while re-signing in academia." Reflective Practice 15, (2), 240-251.2014.

[23] Fleming, Paul. "Reflection-a neglected art in health promotion." Health Education Research 22(5), 658-664.2007.

[24] Taole, M. J. "Reflective Experiences of Post Graduate Certificate in Education Students during Teaching Practice." Research in Higher Education Journal 172012.

[25] Mays, Tony, Mary Grosser, and Lizette de Jager. Getting practical: A guide to teaching and learning. Oxford University Press, Cape Town. 2012.

[26] Taole, Matshidiso Joyce, and Ailwei Solomon Mawela. "A 4 reflective practice approach." Teacher Professional Knowledge and Development for Reflective and Inclusive Practices, 192, 36. 2017.

[27] Fani, Tayebeh, and Farid Ghaemi. "Implications of Vygotsky's zone of proximal development (ZPD) in teacher education: ZPTD and self-scaffolding." Procedia-Social and Behavioral Sciences 29, 1549-1554, 2011.

[28] Shabani, Karim, Mohamad Khatib, and Saman Ebadi. "Vygotsky's zone of proximal development: Instructional implications and teachers' professional development." English language teaching 3(4), 237-248, 2010.

[29] Lee, Carol D. "Signifying in the zone of proximal 
development." In An introduction to Vygotsky, 259-289. Routledge, 2012.

[30] Warford, Mark K. "The zone of proximal teacher development." Teaching and teacher education 27(2), 252-258, 2011

[31] De Gagne, Jennie C., and Kelley J. Walters. "The lived experience of online educators: Hermeneutic phenomenology." Journal of Online Learning and Teaching 6(2), 357-366. 2010.

[32] De Gagne, Jennie C. "Exploring the experience of educators who teach online: A multi-method qualitative study." PhD diss., Northcentral University, 2009.

[33] Painter, Desmond, M. Terre Blanche, and Jill Henderson. "Critical psychology in South Africa: Histories, themes and prospects." Annual Review of Critical Psychology 5, 212-235. 2006.
[34] Flick, Uwe. An introduction to qualitative research. sage, 2018.

[35] Denzin, Norman K., and Yvonna S. Lincoln, eds. The Sage handbook of qualitative research. Sage Publications, 2017.

[36] Marshall, Catherine, and Gretchen B. Rossman. Designing qualitative research. Sage Publications, 2014.

[37] Birks, Melanie. "Quality in qualitative research." Qualitative methodology: A practical guide, 221-236. 2014.

[38] Golafshani, Nahid. "Understanding reliability and validity in qualitative research." The qualitative report 8(4), 597-607. 2003.

[39] Patton, Michael Quinn. "Qualitative research." Encyclopedia of statistics in behavioral science, 2005.

[40] Gavin, Helen. "Thematic analysis." Understanding research methods and statistics in psychology, 273-282. 2008. 